\title{
Systematic Derivation for Quadrature Oscillators Using CCCCTAs
}

\author{
YongAn $L I^{1,2}$ \\ ${ }^{1}$ School of Information and Engineering, Shaanxi Inst. of International Trade \& Commerce, Xi'an 712046, China \\ ${ }^{2}$ School of Physics and Electronic Engineering, Xianyang Normal University, Xianyang 712000, China
}

lya6189@tom.com

\begin{abstract}
According to 16 nullor-mirror models of the current-controlled current conveyor transconductance amplifier (CCCCTA) and using nodal admittance matrix (NAM) expansion method, three different classes of the double-mode quadrature oscillators employed CCCCTAs and two grounded capacitors are synthesized. The class I oscillators have 32 different forms, the class II oscillators have 16 different forms, and the class III oscillators have four different forms. In all, 52 quadrature oscillators using CCCCTAs are obtained. Having used canonic number of components, the circuits are easy to be integrated and the condition for oscillation and the frequency of oscillation can be tuned by tuning bias currents of the CCCCTAs. The circuit analysis and simulation results have been included to support the generation method.
\end{abstract}

\section{Keywords}

Quadrature oscillator, CCCCTA, systematic synthesis, nodal admittance matrix expansion

\section{Introduction}

The NAM expansion method has found wide applications since it was proposed [1-15]. The literature on gyrators, oscillators and filters has explained this viewpoint. However, most of the circuits mentioned in earlier works are based on current conveyor (CCII), inverting current conveyor (ICCII), operational transconductance amplifier (OTA), current differencing transconductance amplifier (CDTA), and current differencing buffered amplifier (CDBA). Very recently, this method has been used in the circuit design employing CCCCTAs [16], but the reported circuits include only gyrators. Because the CCCCTA has attracted considerable attention and a number of CCCCTAbased filters and oscillators have been reported [17-24], it is necessary that using NAM expansion method synthesizes CCCCTA-based circuits except gyrators.

The paper aims at using NMA expansion method to synthesize the quadrature oscillators employing CCCCTAs. First, according to the different forms of the
NAM stamp expanded, the oscillators are classified as three different classes. Next, using NAM expansion method and the nullor-mirror models of the CCCCTA, three different classes of the double-mode oscillators with two grounded capacitors are considered. The class I oscillators, employing two CCCCTAs or two ICCCCTAs or one CCCCTA and ICCCCTA, have 32 different forms. The class II oscillators, employing one CCCCTA or one ICCCCTA with balance outputs and one CCCII or ICCCII, have 16 different forms. The class III oscillators employing one CCCCTA with balance outputs have four different forms. Since the circuits use fewer active elements and grounded capacitors, the circuits are easy to be integrated, and the class I oscillators also provide the attractive feature of linear, independent, and electronic control of the oscillation frequency and the condition for oscillation. Finally, the validity of the synthesized circuit is verified by means of circuit analysis and computer simulation.

\section{Basis of Circuit Synthesis}

\subsection{Basic Concept of CCCCTA}

Fig. 1 shows the symbols of various CCCCTAs and (1) presents the terminal relations of the CCCCTAs [16].

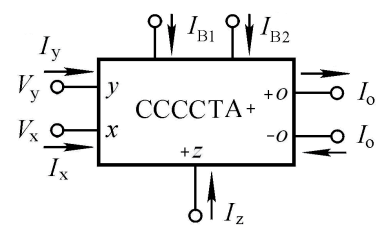

(a)

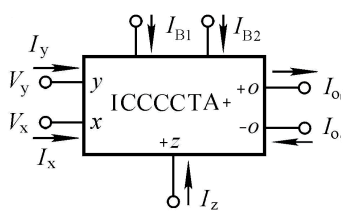

(c)

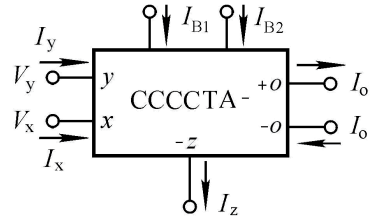

(b)

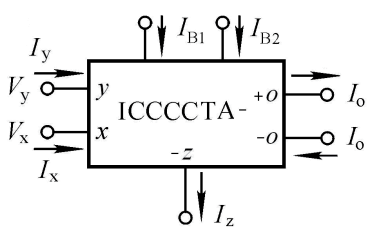

(d)
Fig. 1. (a) Symbol of CCCCTA+. (b) Symbol of CCCCTA-. (c) Symbol of ICCCCTA+. (d) Symbol of ICCCCTA-. 


$$
I_{y}=0, \quad V_{x}=R_{x} I_{x} \pm V_{y} \quad I_{z}=I_{x}, \quad I_{x}=g_{m} V_{z} .
$$

Here, the "+" notation indicates CCCCTA+ and CCCCTA-, and the "-" notation indicates ICCCCTA+ and ICCCCTA-.

For a CCCCTA implemented with bipolar technology, the parasitic resistance and transconductance gain of the CCCCTA could respectively be expressed as

$$
R_{x}=\frac{V_{T}}{2 I_{B 1}}, g_{m}=\frac{I_{B 2}}{2 V_{T}} .
$$

Here, $I_{B 1}$ and $I_{B 2}$ are the DC bias currents of the CCCCTA and $V_{T}$ is the thermal voltage.

\subsection{NAM of Quadrature Oscillators}

The quadrature oscillators to be synthesized in this paper belong to two integrator loop oscillators, whose the block diagram representation is shown in Fig. 2. Routine analysis of the circuit gives the following state equation:

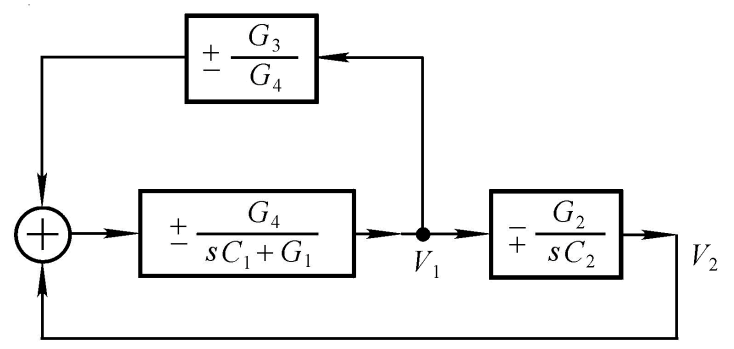

Fig. 2. Block diagram of two integrator loop oscillator.

$$
\left[\begin{array}{cc}
s C_{1}+G_{1}-G_{3} & \mp G_{4} \\
\pm G_{2} & s C_{2}
\end{array}\right]\left[\begin{array}{c}
V_{1} \\
V_{2}
\end{array}\right]=0 .
$$

The NAM equations of the oscillators are then

$$
\begin{gathered}
Y=\left[\begin{array}{cc}
s C_{1}+G_{1}-G_{3} & -G_{4} \\
G_{2} & s C_{2}
\end{array}\right], \\
Y=\left[\begin{array}{cc}
s C_{1}+G_{1}-G_{3} & G_{4} \\
-G_{2} & s C_{2}
\end{array}\right] .
\end{gathered}
$$

Hence, the condition and frequency for oscillation are given by

$$
G_{3} \geq G_{1}, \omega_{o}=\sqrt{\frac{G_{2} G_{4}}{C_{1} C_{2}}} .
$$

What is even more important is that adjusting $G_{3}$ or $G_{1}$ can linearly turn the condition for oscillation, and trimming $G$, if $G_{2}=G_{4}=G$, can linearly adjust the frequency of oscillation. This means that the circuits provide the attractive feature of independent control of the oscillation frequency and the oscillation condition.

\section{Systematic Synthesis of Quadrature Oscillators}

\subsection{Synthesis of Class I Oscillators}

On the basis of the NAM expansion method, starting from (4a), and taking into account the class I oscillators with six nodes, the first step in the NAM expansion is to add four blank rows and columns, and then use a first nullator to link columns 1 and 3 to move $G_{1}$ to the position 1,3 . The first norator is connected between rows 1 and 3 to move $G_{1}$ to the position 3,3. A second nullator is then connected columns 1 and 4 to move $G_{2}$ to the position 2, 4 . A second norator is connected between rows 2 and 4 to move $G_{2}$ to the position 4,4 .

A third nullator is connected between columns 1 and 5 to move $-G_{3}$ to the position 1,5 . A first current mirror is connected rows 1 and 5 to move $-G_{3}$ to be $G_{3}$ at the position 5, 5. A four nullator is then connected columns 2 and 6 to move $-G_{4}$ to the position 1, 6. At last, a second current mirror is connected rows 1 and 6 to move $-G_{4}$ to be $G_{4}$ at the position 6,6 . The NAM matrix with the added nullormirror elements represented by bracket notation is shown in (6).

$$
Y=\left[\begin{array}{cccccc}
s C_{1} & 0 & 0 & 0 & 0 & 0 \\
0 & s C_{2} & 0 & 0 & 0 & 0 \\
0 & 0 & G_{1} & 0 & 0 & 0 \\
0 & 0 & 0 & G_{2} & 0 & 0 \\
0 & 0 & 0 & 0 & G_{3} & 0 \\
0 & 0 & 0 & 0 & 0 & G_{4}
\end{array}\right] .
$$

Here, $G_{1}, G_{2}, G_{3}$, and $G_{4}$ denote the admittances between nodes 3, 4, 5, 6 and ground, respectively. As (6) shows, this expanded matrix contains four different pairs of pathological elements, two grounded capacitors, and four grounded admittances, namely $G_{1}, G_{2}, G_{3}$, and $G_{4}$.

The nullor-mirror equivalent circuit for the oscillator described by (6) is shown in Fig. 3. Using the nullor-mirror descriptions for CCCCTA [16] and keeping Fig. 3 in mind, four equivalent CCCCTA-based realizations can be achieved, as shown in Fig. 4.

It is noteworthy that in Fig. 4(a), $G_{1}=1 / R_{\mathrm{x} 1}=2 I_{\mathrm{B} 11} / V_{\mathrm{T}}$, $G_{3}=g_{\mathrm{m} 1}=I_{\mathrm{B} 12} / 2 V_{\mathrm{T}}, G_{2}=1 / R_{\mathrm{x} 2}=2 I_{\mathrm{B} 21} / V_{\mathrm{T}}, G_{4}=g_{\mathrm{m} 2}=I_{\mathrm{B} 22} / 2 V_{\mathrm{T}} ;$ in Fig. 4(b), $G_{3}=1 / R_{\mathrm{x} 1}=2 I_{\mathrm{B} 11} / V_{\mathrm{T}}, \quad G_{1}=g_{\mathrm{m} 1}=I_{\mathrm{B} 12} / 2 V_{\mathrm{T}}$, $G_{2}=1 / R_{\mathrm{x} 2}=2 I_{\mathrm{B} 21} / V_{\mathrm{T}}, \quad G_{4}=g_{\mathrm{m} 2}=I_{\mathrm{B} 22} / 2 V_{\mathrm{T}} ; \quad$ in Fig. 4(c), $G_{3}=1 / R_{\mathrm{x} 1}=2 I_{\mathrm{B} 11} / V_{\mathrm{T}}, G_{1}=g_{\mathrm{m} 1}=I_{\mathrm{B} 12} / 2 V_{\mathrm{T}}, G_{4}=1 / R_{\mathrm{x} 2}=2 I_{\mathrm{B} 21} / V_{\mathrm{T}}$, $G_{2}=g_{\mathrm{m} 2}=I_{\mathrm{B} 22} / 2 V_{\mathrm{T}} ; \quad$ in Fig. 4(d), $G_{1}=1 / R_{\mathrm{x} 1}=2 I_{\mathrm{B} 11} / V_{\mathrm{T}}$, $G_{3}=g_{\mathrm{m} 1}=I_{\mathrm{B} 12} / 2 V_{\mathrm{T}}, G_{4}=1 / R_{\mathrm{x} 2}=2 I_{\mathrm{B} 21} / V_{\mathrm{T}}, G_{2}=g_{\mathrm{m} 2}=I_{\mathrm{B} 22} / 2 V_{\mathrm{T}}$. 


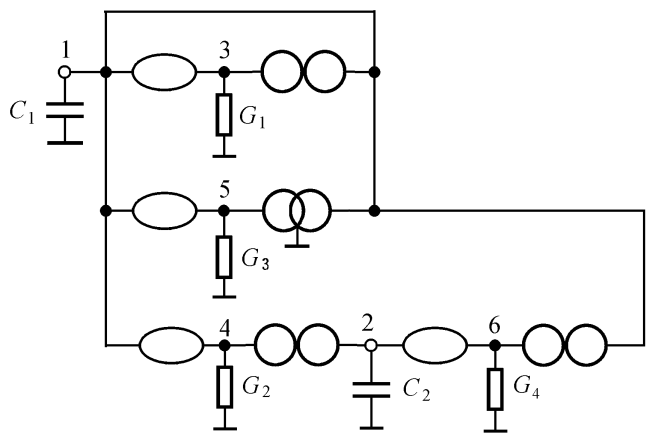

Fig. 3. Nullor-mirror equivalent model described by (6).

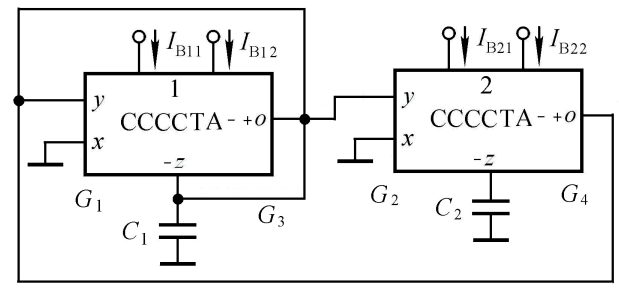

(a)

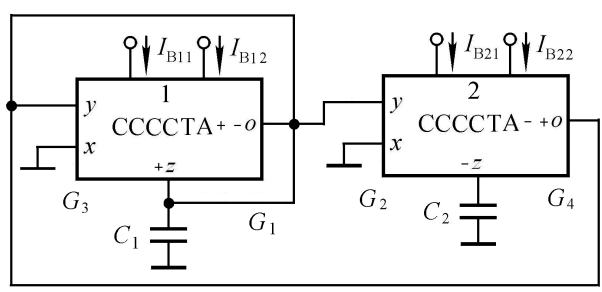

(b)

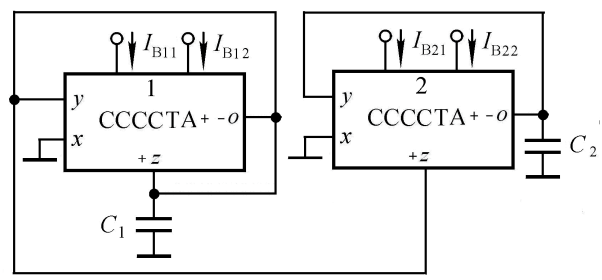

(c)

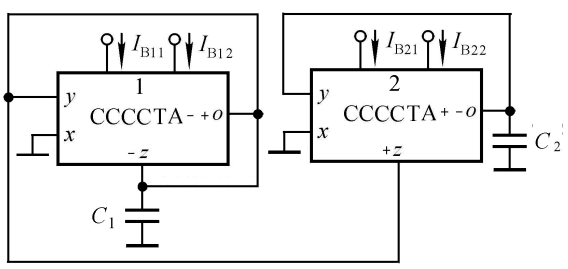

(d)

Fig. 4. Four of 32 equivalent realizations for type I oscillators.

Likewise, starting from (4a) and (4b), and applying all possible combinations of the added nullor-mirror elements will yield 32 different forms of the expanded matrixes, resulting in 32 different forms of the equivalent nullormirror models. 32 equivalent CCCCTA-based circuits are then synthesized. The remaining implementations are omitted to limit the paper length. Of course, readers can also obtain them by changing local feedback polarity and amplifier polarity with the aim to provide global positive feedback gain.

\subsection{Synthesis of Class II Oscillators}

In order to realize the class II oscillators using CCCCTAs, starting from (4a), adding four blank rows and and columns, and supposing $G_{2}=G_{3}=G, G_{1}=G_{4}=G^{\prime}$, following successive NAM expansion steps with the added nullor-mirror elements represented by bracket notation will yield the matrix represented by (7).

$$
\left.Y=\left[\begin{array}{cccccc}
\overbrace{s C_{1}} & 0 & 0 & \overbrace{}^{0} & 0 & 0 \\
0 & s C_{2} & 0 & 0 & 0 & 0 \\
0 & 0 & G & -G & 0 & 0 \\
0 & 0 & -G & G & 0 & 0 \\
0 & 0 & 0 & 0 & G^{\prime} & -G^{\prime} \\
0 & 0 & 0 & 0 & -G^{\prime} & G^{\prime}
\end{array}\right]\right\}
$$

Here, $G^{\prime}$ are the admittance between nodes 5 and 6 , while the $G$ are the admittance between nodes 3 and 4. It is easy to see that this expanded matrix contains four different pairs of pathological elements and two floating admittance, namely $G$ and $G$ '. The nullor-mirror equivalent model is shown in Fig. 5.

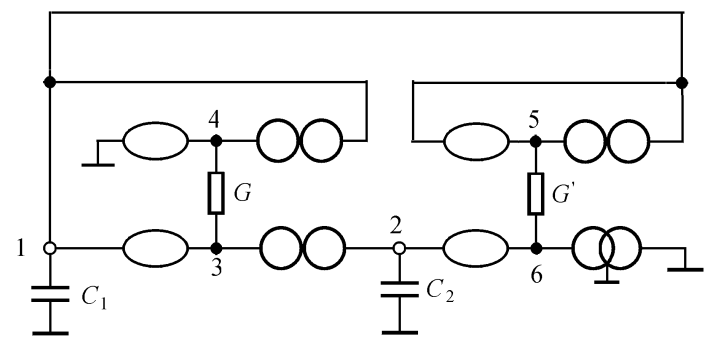

Fig. 5. Nullor-mirror equivalent model described by (7).

Using the nullor-mirror descriptions for CCCCTA and keeping in mind of Fig. 5, one equivalent CCCCTAbased realizations can be achieved, as shown in Fig. 6. It should be noted that in Fig. $6, G^{\prime}=1 /\left(R_{\mathrm{x} 1}+R_{\mathrm{x} 2}\right)$ $=2\left(I_{\mathrm{B} 11}+I_{\mathrm{B} 21}\right) / V_{\mathrm{T}}, G=g_{\mathrm{m} 1}=I_{\mathrm{B} 12} / 2 V_{\mathrm{T}}$.

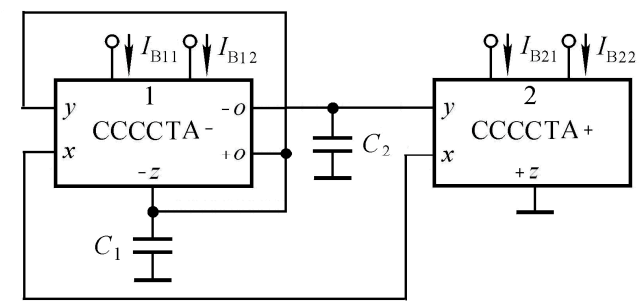

Fig. 6. One of 16 equivalent realizations for type II oscillators.

Similarly, starting from (4a) and (4b), and applying all possible combinations of the added nullor-mirror elements will yield 32 different forms of the expanded matrixes, resulting in 32 different forms of the equivalent nullormirror models. However, only 16 equivalent CCCCTAbased circuits are synthesized. The remaining implementations are omitted. 


\subsection{Synthesis of Class III Oscillators}

In order to realize the class III oscillators using CCCCTAs, starting from (4a), adding three blank rows and columns, and supposing $G_{1}=0, G_{2}=G_{3}=G$, following successive NAM expansion steps with the added nullormirror elements represented by bracket notation will yield the matrix represented by (8).

$$
\left.Y=\left[\begin{array}{ccccc}
s C_{1} & 0 & 0 & 0 & 0 \\
0 & s C_{2} & 0 & 0 & 0 \\
0 & 0 & G & -G & 0 \\
0 & 0 & -G & G & 0 \\
0 & 0 & 0 & 0 & G_{4}
\end{array}\right]\right] \succ \text {. }
$$

Here, $G$ is the admittance between nodes 3 and 4 , while $G_{4}$ is the admittance between node 5 and ground. It can be easily seen that this expanded matrix contains three different pairs of pathological elements, one grounded admittance $G_{4}$, and one floating admittance $G$.

The nullor-mirror equivalent model described by (8) is shown in Fig. 7.

Using the nullor-mirror descriptions for CCCCTA and bearing in mind of Fig. 7, one equivalent CCCCTAbased realizations can be achieved, as shown in Fig. 8(a).

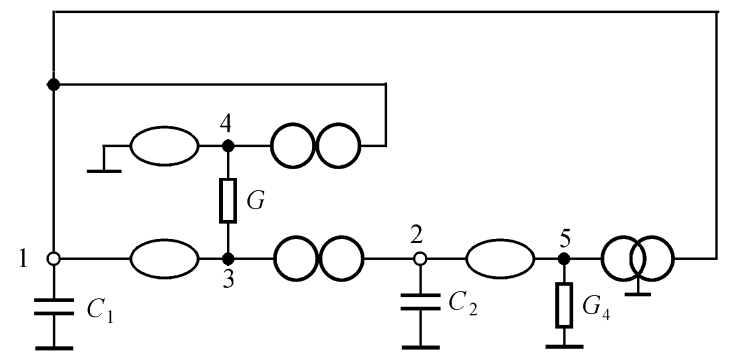

Fig. 7. Nullor-mirror equivalent model described by (8).

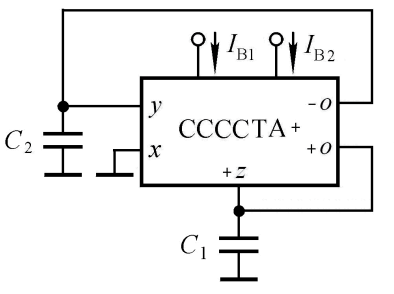

(a)

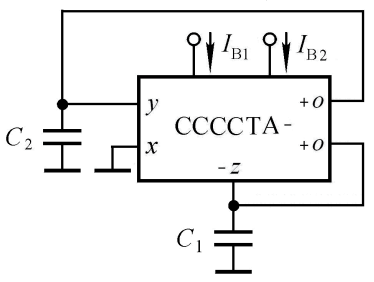

(c)

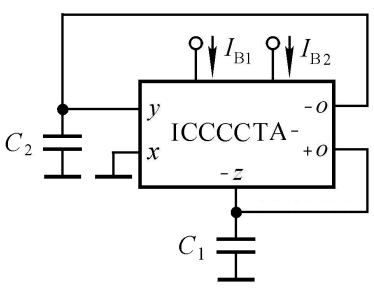

(b)

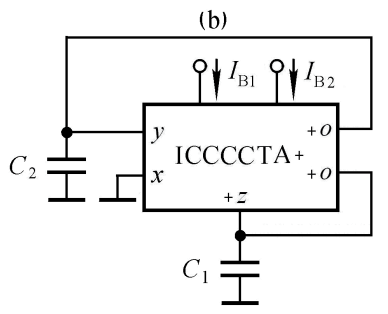

(d)
Fig. 8. Four equivalent realizations for type III oscillators.
Similarly, starting from (4a) and (4b), and applying all possible combinations of the added nullor-mirror elements will yield 16 different forms of the expanded matrixes, resulting in 16 different forms of the equivalent nullormirror models. However, only four equivalent CCCCTAbased circuits are synthesized, as shown in Fig. 8, (a)-(d), where $G_{4}=1 / R_{\mathrm{x}}=2 I_{\mathrm{B} 1} / V_{\mathrm{T}}, G=g_{\mathrm{m}}=I_{\mathrm{B} 2} / 2 V_{\mathrm{T}}$. It can be readily seen that the class III oscillators, employed one CCCCTA with double outputs and two grounded capacitors, possess four different forms.

\section{Circuit Analysis}

\subsection{Analysis of Class I Oscillators}

As an example of class I oscillators analysis, consider only the circuit in Fig. 4(a) and add two current outputs, $I_{01}$ and $I_{\mathrm{o} 2}$, by the current source technique, as shown in Fig. 9. A routine analysis of the circuit in Fig. 9 yields the following equations:

$$
\begin{gathered}
V_{x 2}=I_{x 2} / G_{2}+V_{y}=0, V_{x 1}=I_{x 1} / G_{1}+V_{y}=0, \\
V_{2}=I_{x 2} / s C_{2}, V_{1}=\left(I_{x 1}+G_{3} V_{y}+G_{4} V_{2}\right) / s C_{1}, \\
I_{o 1}=s C_{2} V_{2}, I_{o 2}=-G_{4} V_{2} .
\end{gathered}
$$

Combining (11), one can obtain the characteristic equation and the transfer functions as follows

$$
\begin{gathered}
s^{2}+\frac{G_{1}-G_{3}}{C_{1}} s+\frac{G_{2} G_{4}}{C_{1} C_{2}}=0, \\
\frac{I_{o 1}}{I_{o 2}}=-j \sqrt{\frac{C_{2} G_{2}}{C_{1} G_{4}}}, \frac{V_{1}}{V_{2}}=-j \sqrt{\frac{C_{2} G_{4}}{C_{1} G_{2}}} .
\end{gathered}
$$

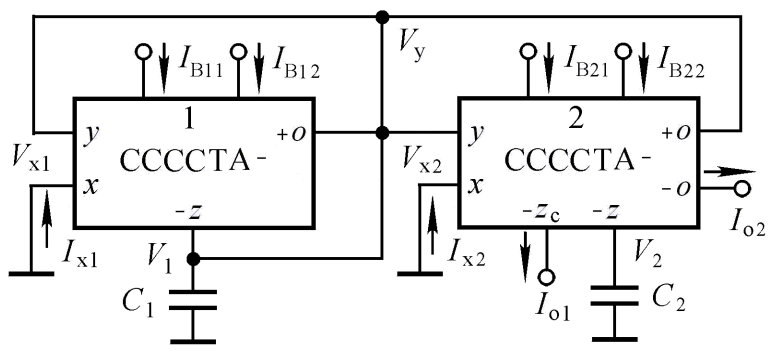

Fig. 9. One of type I oscillators with double-mode outputs.

It can be seen that the oscillation condition and frequency of the oscillator are the same as (5). As (11) shows, the circuit can provide not only two quadrature current outputs but also two quadrature voltage outputs.

\subsection{Analysis of Class II Oscillators}

For the circuit in Fig. 6, using the current source technique and adding one current output $I_{02}$ result in the circuit in Fig. 10. An analysis of Fig. 10 gives 


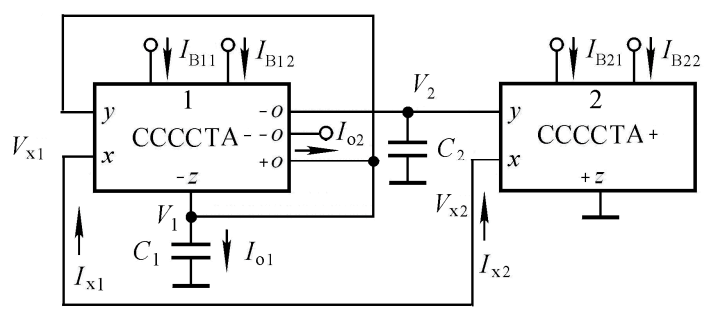

Fig. 10. One of type II oscillators with double-mode outputs.

$$
\begin{gathered}
V_{2}=-G V_{1} / s C_{2}, V_{1}=\left(I_{x 1}+G V_{1}\right) / s C_{1}, \\
V_{x 1}=R_{x 1} I_{x 1}+V_{1}=V_{x 2}=R_{x 2} I_{x 2}+V_{2}, \\
I_{x 1}=-I_{x 2}, \quad R_{x 1}+R_{x 2}=1 / G^{\prime}, \\
I_{o 2}=-G V_{1}, I_{o 1}=V_{1} s C_{1} .
\end{gathered}
$$

Combining the above equations yields

$$
\begin{gathered}
s^{2}+\frac{G^{\prime}-G}{C_{1}} s+\frac{G G^{\prime}}{C_{1} C_{2}}=0, \\
\frac{I_{o 1}}{I_{o 2}}=-j \sqrt{\frac{C_{1} G^{\prime}}{C_{2} G}}, \frac{V_{1}}{V_{2}}=-j \sqrt{\frac{C_{2} G^{\prime}}{C_{1} G}} .
\end{gathered}
$$

From (13), the condition and frequency for oscillation are

$$
G \geq G^{\prime}, \omega_{o}=\sqrt{\frac{G G^{\prime}}{C_{1} C_{2}}} .
$$

From (15) it can be seen that the control for the oscillation frequency and the oscillation condition is dependent. From (14), it can also be seen that the circuit can also provide two double-mode quadrature outputs. However, the current output, $I_{\mathrm{o} 1}$, has no high output impedance.

\subsection{Analysis of Class III Oscillators}

Consider only the circuit in Fig. 8(a). Using the current source technique and adding two current outputs, $I_{01}$ and $I_{\mathrm{o} 2}$, give the quadrature oscillator in Fig. 11 .

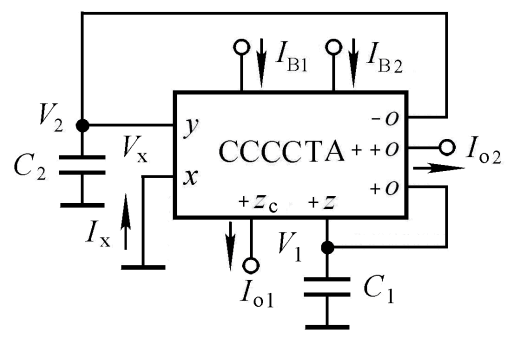

Fig. 11. One of type III oscillators with double-mode outputs. equations:

By inapection of Fig. 11, obtain the following

$$
\begin{gathered}
V_{2}=-G V_{1} / s C_{2}, V_{1}=\left(-I_{x}+G V_{1}\right) / s C_{1}, \\
V_{x}=I_{x} / G_{4}+V_{2}=0, I_{o 1}=-I_{x}, I_{o 2}=G V_{1} .
\end{gathered}
$$

Combining the above equations produces the following characteristic equation and transfer functions:

$$
\begin{gathered}
s^{2}-\frac{G}{C_{1}} s+\frac{G G_{4}}{C_{1} C_{2}}=0 \\
\frac{I_{o 1}}{I_{o 2}}=j \sqrt{\frac{C_{1} G_{4}}{C_{2} G}}, \frac{V_{1}}{V_{2}}=-j \sqrt{\frac{C_{2} G_{4}}{C_{1} G}} .
\end{gathered}
$$

From (17), the condition and frequency for oscillation are

$$
G \geq 0, \omega_{o}=\sqrt{\frac{G G_{4}}{C_{1} C_{2}}} .
$$

It is clear that the oscillation condition and frequency of the oscillator are the same as (5). (18) shows that the circuit provides two double-mode quadrature outputs.

The above results have been tabulated, as shown in Tab. 1. It can be seen that the synthesized quadrature oscillators employ grounded capacitors and enjoy low sensitivities. It can also be seen that the class III oscillators employ only one CCCCTA but they require matched conditions and the control for oscillation condition is not easily realized, this is due to the fact that the BJTs in CCCCTA are not in the forward-active mode when $G=0$. For the class II oscillators, although the oscillation condition and oscillation frequency can be electronically tuned, this control is not independent, and the oscillators also require the matched conditions. Therefore, the class I oscillators are the best because they employ two CCCCTAs and do not require the matched conditions, and their parameters can be linearly, independently, and electronically tuned by trimming bias currents of the CCCCTAs. The class I oscillators are compared with several quadrature oscillators reported in the reference [25-31] and the results are given in Tab. 2.

In the non-ideal case, to limit the paper length, only the circuit of Fig. 9 in the class I oscillators is considered. To highlight the main effects of the parasitic admittances, only the parasitic admittances at terminals $o, y$, and $z$ are taken into account. Re-analysis of the circuit in Fig. 9 results in the following equations:

$$
\begin{aligned}
& V_{x 2}=I_{x 2} / G_{2}+V_{y}=0, V_{x 1}=I_{x 1} / G_{1}+V_{y}=0, \\
& V_{2}=I_{x 2} /\left(s C_{2}+s C_{p 2}+G_{p 2}\right), \\
& V_{1}=\left(I_{x 1}+G_{3} V_{y}+G_{4} V_{2}\right) /\left(s C_{1}+s C_{p 1}+G_{p 1}\right), \\
& I_{o 1}=\left(s C_{2}+s C_{p 2}+G_{p 2}\right) V_{2}, I_{o 2}=-G_{4} V_{2}
\end{aligned}
$$

where $G_{\mathrm{p} 1}=G_{\mathrm{O} 1}+G_{\mathrm{y} 1}+G_{\mathrm{z} 1}+G_{\mathrm{O} 2}+G_{\mathrm{y} 2}$, which are the parasitic conductances at terminals $o, y$, and $z$ of the $\mathrm{CCCCTA}_{1}$ and at terminals $o$ and $y$ of the $\mathrm{CCCCTA}_{2}$, respectively; $\mathrm{C}_{\mathrm{p} 1}=C_{\mathrm{O} 1}+C_{\mathrm{y} 1}+C_{\mathrm{z} 1}+C_{\mathrm{O} 2}+C_{\mathrm{y} 2}$, which respectively denote the parasitic capacitances at terminals $o, y$, and $z$ of the $\operatorname{CCCCTA}_{1}$ and at terminals $o$ and $y$ of the $\mathrm{CCCCTA}_{2} ; G_{\mathrm{p} 2}=G_{\mathrm{z} 2}$, which is the parasitic conductance at terminal $z$ of the $\mathrm{CCCCTA}_{2} ; \mathrm{C}_{\mathrm{p} 2}=C_{\mathrm{z} 2}$, which denotes the parasitic capacitance at terminal $z$ of the $\mathrm{CCCCTA}_{2}$. 


\begin{tabular}{|c|c|c|c|c|c|c|c|}
\hline Class & $\begin{array}{c}\text { No. of } \\
\text { oscillators }\end{array}$ & $\begin{array}{c}\text { No. of active } \\
\text { devices }\end{array}$ & OC & OF & $\begin{array}{c}\text { Independent control for } \\
\text { OC and OF }\end{array}$ & $\begin{array}{c}\text { Output } \\
\text { impedances }\end{array}$ & $\begin{array}{c}\text { Initial } \\
\text { conditions }\end{array}$ \\
\hline I & 32 & Two CCCCTAs & $G_{3} \geq G_{1}$ & $\sqrt{\frac{G_{2} G_{4}}{C_{1} C_{2}}}$ & Yes & High \\
\hline II & 16 & $\begin{array}{c}\text { One CCCCTA } \\
\text { and one CCCII }\end{array}$ & $G \geq G$ & $\sqrt{\frac{G G^{\prime}}{C_{1} C_{2}}}$ & No & $\begin{array}{c}\text { High except } I_{01} \\
\text { output }\end{array}$ & $\begin{array}{c}G_{2}=G_{3}=G \\
G_{1}=G_{4}=G^{\prime}\end{array}$ \\
\hline III & 4 & One CCCCTA & $G \geq 0$ & $\sqrt{\frac{G G_{4}}{C_{1} C_{2}}}$ & No & Nigh & $G_{2}=0$, \\
$G_{2}=G$
\end{tabular}

Tab.1. Properties for the three different types of quadrature oscillators.

\begin{tabular}{|c|c|c|c|c|c|c|c|c|}
\hline Ref & ABB & $\begin{array}{c}\text { No. of } \\
\text { ABB }\end{array}$ & $\begin{array}{c}\text { No. of } \\
R+C\end{array}$ & $\begin{array}{c}\text { Grounded C } \\
\text { only }\end{array}$ & $\begin{array}{c}\text { Linear independent } \\
\text { electronic tune for OC }\end{array}$ & $\begin{array}{c}\text { Linear independent } \\
\text { electronic tune for OF }\end{array}$ & $\begin{array}{c}\text { Current } \\
\text { mode }\end{array}$ & $\begin{array}{c}\text { Systematic } \\
\text { synthesis }\end{array}$ \\
\hline$[10]$ & Op Amp & 2 & $5+2$ & No & No & No & No & No \\
\hline$[10]$ & CFOA & 2 & $3+2$ & Yes & No & No & No & Yes \\
\hline$[7]$ & CC II & 3 & $3+2$ & Yes & No & Yo & Yes & Yes \\
\hline$[25]$ & OTA & 4 & $1+2$ & Yes & Yes & No & Yes & No \\
\hline$[26]$ & CDTA & 2 & $1+2$ & Yes & Yes & Yes & Yes & No \\
\hline$[27]$ & MCDTA & 1 & $0+2$ & Yes & No & No & Yes & No \\
\hline$[28]$ & MOCCCDTA & 1 & $0+2$ & Yes & No & Yes & Yes & No \\
\hline$[29]$ & CCCDTA & 2 & $0+2$ & Yes & Yes & No & Yes & No \\
\hline$[30]$ & CFTA & 2 & $2+2$ & Yes & Yes & Yes & Yes & No \\
\hline$[31]$ & ZC-CFTA & 4 & $0+2$ & Yes & Yes & No & No & No \\
\hline$[17]$ & CCTA & 1 & $2+2$ & Yes & No & No & No \\
\hline$[21]$ & CCTA & 2 & $0+2$ & Yes & No & No & Yes & No \\
\hline$[22]$ & MOCCCCTA & 1 & $0+2$ & Yes & No & Yes & Yes & No \\
\hline$[24]$ & CCCCTA & 2 & $0+2$ & Yes & Yes & Yes & Yes & \multirow{2}{*}{ Yes } \\
\hline $\begin{array}{c}\text { This } \\
\text { work }\end{array}$ & CCCCTA & 2 & $0+2$ & Yes & Yes & & & \\
\hline
\end{tabular}

Tab.2. Comparison between various quadrature oscillators.

Combining the above equations yields the modified oscillation condition and oscillation frequency:

$$
\begin{gathered}
G_{3} \geq G_{1}+G_{p 1}+\frac{C_{1}+C_{p 1}}{C_{2}+C_{p 2}} G_{p 2}, \\
\omega_{o m}=\sqrt{\frac{G_{2} G_{4}+\left(G_{1}-G_{3}+G_{p 1}\right) G_{p 2}}{\left(C_{1}+C_{p 1}\right)\left(C_{2}+C_{p 2}\right)}} .
\end{gathered}
$$

Therefore, it can be seen that adjusting $G_{1}$ or $G_{3}$ can turn the oscillation condition, but this affects the oscillation frequency, whereas trimming $G_{2}$ or $G_{4}$ can adjusted the oscillation frequency without affecting the oscillation condition. Ignoring the second-order infinitesimal $G_{\mathrm{p} 1} G_{\mathrm{p} 2}$ and $C_{\mathrm{p} 1} C_{\mathrm{p} 2}$, and applying $\sqrt{1+x} \approx 1+x / 2$, for $|x|<<1$, (21) simplifies to

$$
\begin{aligned}
& G_{3} \geq G_{1}+G_{p 1}+\frac{C_{1}}{C_{2}} G_{p 2}, \\
& \omega_{o m} \approx \omega_{o}\left(1-\frac{C_{\mathrm{p} 1}}{2 \mathrm{C}_{1}}-\frac{C_{\mathrm{p} 2}}{2 C_{2}}\right) .
\end{aligned}
$$

Therefore, taking into account non-ideal factors, the modified oscillation condition shows that $G_{3}$ must be slightly greater than $G_{1}$. The modified oscillation frequency shows that the oscillation frequency becomes smaller. For sinusoidal steady state, using (21) and ignoring the secondorder infinitesimal, the transfer functions can be derived as

$$
\begin{gathered}
\frac{I_{o 1}}{I_{o 2}}=\sqrt{\frac{\left(C_{2}+C_{p 2}\right) G_{2}}{\left(C_{1}+C_{p 1}\right) G_{4}}} \angle-180^{\circ}+\operatorname{tg}^{-1} \frac{1}{G_{p 2}} \sqrt{\frac{C_{2}+C_{p 2}}{C_{1}+C_{p 1}} G_{2} G_{4}}, \\
\frac{V_{1}}{V_{2}}=\sqrt{\frac{\left(C_{2}+C_{p 2}\right) G_{4}}{\left(C_{1}+C_{p 1}\right) G_{2}}} \angle-180^{\circ}+\operatorname{tg}^{-1} \frac{1}{G_{p 2}} \sqrt{\frac{C_{2}+C_{p 2}}{C_{1}+C_{p 1}} G_{2} G_{4}} .
\end{gathered}
$$

It is clear that the phase differences for two output signals are not $90^{\circ}$ due to non-ideal factors.

It is desired to minimize the distortion in an oscillator, a circuit with precise auto-compensating AGC systems is necessary, as shown in the literature [32-33]. $V_{1}$ acts as the input of the AGC, $I_{\mathrm{B} 11}$ acts as the output of the AGC. As the oscillation grows, the amplitude of $I_{\mathrm{o} 2}$ would increase and the output of the AGC, $I_{\mathrm{B} 11}$, would also increase. From (22), the amplitude would decrease as the oscillation becomes weak. At last, the amplitude will automatically stabilize at some intermediate level. 


\section{Computer Verification}

In order to test the performances of the proposed circuits, the sub-circuit for CCCCTA was created by using the transistor model of PR200N and NR200N [16], [23]. Then only the circuit in Fig. 9 was simulated by means of NI MULTISIM 11.0 software. When $I_{\mathrm{B} 12}=163 \mu \mathrm{A}$, $I_{\mathrm{B} 11}=40 \mu \mathrm{A}$, then $G_{3}>G_{1}$. Imposing $C_{1}=C_{2}=1 \mathrm{nF}$, and $G_{2}=G_{4}$, namely $I_{\mathrm{B} 22}=4 I_{\mathrm{B} 21}=I_{\mathrm{B}}=163 \mu \mathrm{A}$, from (2), (5), and (11), the design value for $f_{\mathrm{o}}$ is $0.5 \mathrm{MHz}$ and $I_{01} / I_{02}=-\mathrm{j}$. The simulation result is shown in Fig. 12.

To illustrate the controllability of $f_{\mathrm{o}}$ by adjusting $I_{\mathrm{B}}$, $I_{\mathrm{B} 12}$ and $I_{\mathrm{B} 11}$ are kept as before. When $I_{\mathrm{B}}$ is $652 \mu \mathrm{A}$, the design value for $f_{\mathrm{o}}$ is $2 \mathrm{MHz}$. The responses simulation result is shown in Fig. 13. When $I_{\mathrm{B}}$ is tuned from $163 \mu \mathrm{A}$ to $652 \mu \mathrm{A}$, the design value for $f_{\mathrm{o}}$ is changed from $500 \mathrm{kHz}$ to $2 \mathrm{MHz}$, as shown in Fig. 14.

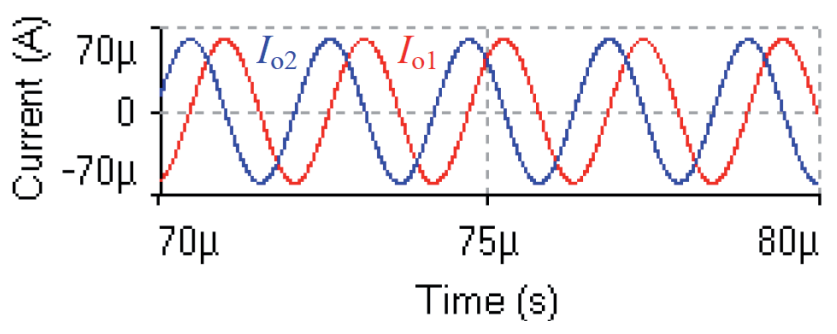

Fig. 12. Simulated results of the oscillator for the design value of $0.5 \mathrm{MHz}$.

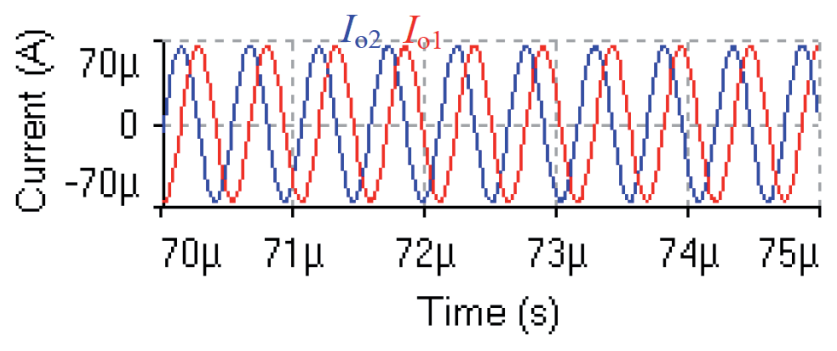

Fig. 13. Simulated results of the oscillator for the design value of $2 \mathrm{MHz}$

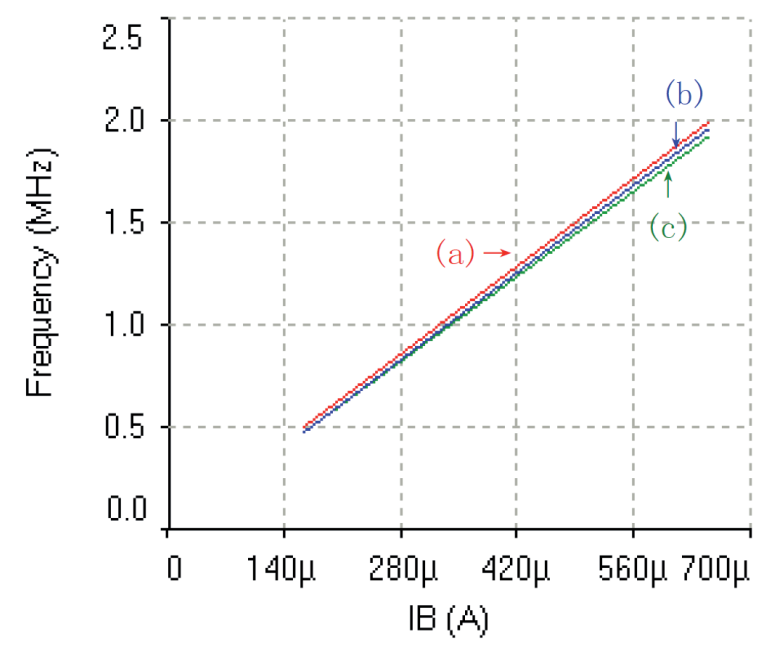

Fig. 14. Simulated dependence of FO on $I_{\mathrm{B}}$ values, (a) ideal, (b) simulated by (5), (c) simulated by (22) with $C_{\mathrm{p} 1}=C_{\mathrm{p} 2}=10 \mathrm{pF}$.
From Fig.12 and Fig.13, during the tuning process, the change of output current levels is maximally about $7 \%$.

From (23), imposing $C_{\mathrm{p} 1}=C_{\mathrm{p} 2}=10 \mathrm{pF}$, $R_{\mathrm{z}}=1 / G_{\mathrm{z} 2}=123 \mathrm{k} \Omega$ [23], and tuning $I_{\mathrm{B}}$ from $163 \mu \mathrm{A}$ to $652 \mu \mathrm{A}$, the phase difference for the two output signals is shown in Fig. 15.

The total harmonic distortions for $I_{02}$ and $I_{01}$ are $1.32 \%$ and $1.21 \%$, respectively. Fig. 16 shows only the simulated output spectrum for $I_{01}$. Consequently, the oscillator can sustain two quadrature output signals with small distortion.

It is noted that the results of circuit simulations are in agreement with theory.

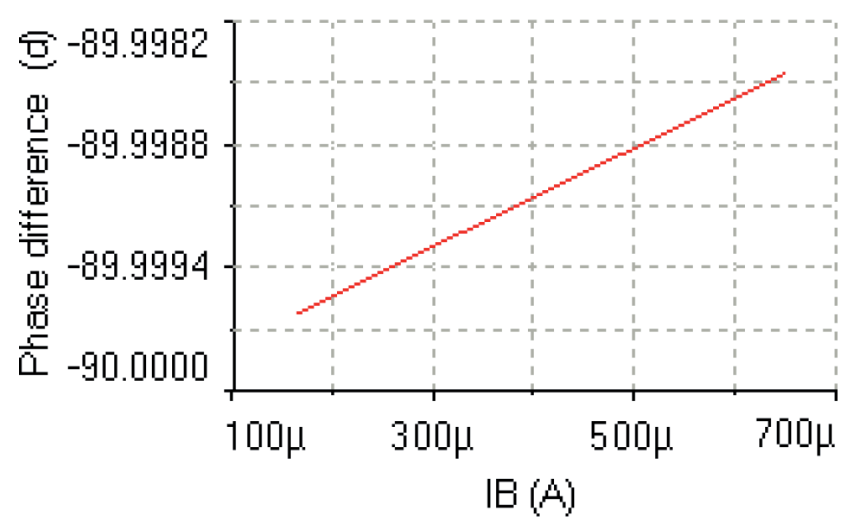

Fig. 15. Simulated dependence of phase difference on $I_{\mathrm{B}}$ values.

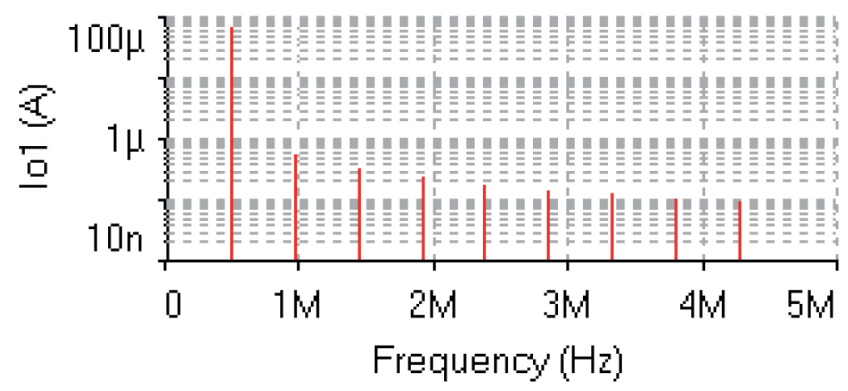

Fig.16. Simulation result of the output spectrum for the design value of $0.5 \mathrm{MHz}$.

\section{Conclusions}

Even though other synthesis approaches are also used to obtain quadrature oscillators, the approach presented in this paper is simple, systematic, and powerful. The main feature of the paper is making use of systematic design method to obtain 52 voltage-mode/current-mode quadrature oscillators. The synthesized double-mode quadrature oscillators also enjoy many advantages, such as electronic control of the oscillation frequency and the oscillation condition, use of grounded capacitors, no externally connected resistors, and so on. The results of circuit analysis and simulation have verified the theory involved. 


\section{References}

[1] HAIGH, D. G. A method of transformation from symbolic transfer function to active-RC circuit by admittance matrix expansion. IEEE Transactions on Circuits and Systems I, 2006, vol. 53, no. 12 , p. 2715-2728. ISSN: 1549-8328. DOI: 10.1109/TCSI.2006.883879

[2] HAIGH, D. G., CLARKE, T. J. W., RADMORE, P. M. Symbolic framework for linear active circuits based on port equivalence using limit variables. IEEE Transactions on Circuits and Systems I, 2006, vol. 53, no. 9, p. 2011-2024. ISSN: 1549-8328. DOI: 10.1109/TCSI.2006.882815

[3] SÁNCHEZ-LÓPEZ, C., CANTE-MICHCOL, B., MORALESLÓPEZ, F. E., CARRASCO-AGUILAR, M. A. Pathological equivalents of $\mathrm{CMs}$ and VMs with multi-outputs. Analog Integrated Circuits and Signal Processing, 2013, vol. 75, no. 1, p. 75-83. ISSN: 0925-1030. DOI: $10.1007 / \mathrm{s} 10470-012-0003-9$

[4] SOLIMAN, A. M. Generation of generalized impedance converter circuits using NAM expansion. Circuits, Systems, and Signal Processing, 2011, vol. 30, no. 5, p. 1091-1114. ISSN: 0278-081X. DOI: $10.1007 / \mathrm{s} 00034-010-9218-0$

[5] SOLIMAN, A. M. Transformation of oscillators using op amps, unity gain cells and CFOA. Analog Integrated Circuits and Signal Processing, 2010, vol. 65, no. 1, p. 105-114. ISSN: 0925-1030. DOI: $10.1007 / \mathrm{s} 10470-010-9458-8$

[6] SOLIMAN, A. M. Generation of current conveyor based oscillators using nodal admittance matrix expansion. Analog Integrated Circuits and Signal Processing, 2010, vol. 65, no. 1, p. 43-59. ISSN: 0925-1030. DOI: 10.1007/s10470-009-9432-5

[7] SOLIMAN, A. M. Generation of CCIIand ICCIIbased Wien oscillators using nodal admittance matrix expansion. $A E \ddot{U}-$ International Journal of Electronics and Communications, 2010, vol. 64, no. 10, p. 971-977. ISSN: 1434-8411. DOI: 10.1016/j.aeue.2009.08.003

[8] LI, Y. A. NAM expansion method for systematic synthesis of OTA-based floating gyrators. AEÜ-International Journal of Electronics and Communications, 2013, vol. 67, no. 4, p. 289-294. ISSN: 1434-8411. DOI: 10.1016/j.aeue.2012.08.012

[9] LI, Y. A. On the systematic synthesis of OTA-based KHN filters. Radioengineering, 2014, vol. 23, no. 1, p. 540-548. ISSN: 12102512

[10] SOLIMAN, A. M. Pathological realizations of the DCVC (CDBA) and applications to oscillators and filters. AEÜ-International Journal of Electronics and Communications, 2013, vol. 75, no. 12, p. 985-992. ISSN: 1434-8411. DOI: 10.1016/j.aeue.2011.03.010

[11] TAN, L. L., LIU, K. H., BAI, Y., TENG, J. F. Construction of CDBA and CDTA behavioural models and the applications in symbolic circuits analysis. Analog Integrated Circuits and Signal Processing, 2013, vol. 75, no. 3, p. 517-523. ISSN: 0925-1030. DOI: $10.1007 / \mathrm{s} 10470-013-0065-3$

[12] LI, Y. A. Systematic synthesis of OTA-based T-T filters using NAME method. Journal of Circuits, Systems, and Computers, 2013, vol. 22, no. 3, p. 1-17. ISSN: 1793-6454. DOI: $10.1142 / \mathrm{S} 0218126613500023$.

[13] LI, Y. A. On the systematic synthesis of OTA-based Wien oscillators. AEÜ-International Journal of Electronics and Communications, 2013, vol. 67, no. 9, p. 754-760. ISSN: 14348411. DOI: $10.1016 /$ j.aeue.2013.03.001

[14] PETRZELA, J. Bilinear reconfigurable filters derived by using matrix method of unknown nodal voltages. In 37th International Conference on Telecommunications and Signal Processing (TSP), Berlin, 2014, p. 358-363. ISBN: 978-80-214-4983- 1.

[15] PETRZELA, J., VYSKOCIL, P., PROKOPEC, J. Fundamental oscillators based on diamond transistors. In Proceedings of 20th International Conference Radioelektronika. Brno (Czech Rep.), 2010, p. 217-220. ISBN: 978-1-4244-6318-3. DOI: 10.1109/RADIOELEK.2010.5478555

[16] LI, Y. A. NAM expansion method for systematic synthesis of floating gyrators using CCCCTAs. Analog Integrated Circuits and Signal Processing, 2015, vol. 82, no. 3, p. 733-743. ISSN: 09251030. DOI: $10.1007 / \mathrm{s} 10470-014-0468-9$

[17] SOTNER, R., JERABEK, J., PROKOP, R., VRBA, K. Current gain controlled CCTA and its application in quadrature oscillator and direct frequency modulator. Radioengineering, 2011, vol. 20, no. 1, p. 317-326. ISSN: 1210-2512

[18] HERENCSAR, N., KOTON, J., VRBA, K. Single CCTA-based universal biquadratic filters employing minimum components. International Journal of Computer and Electrical Engineering, 2009, vol. 1, no. 3, p. 307-310. ISSN 1793-8163. DOI: 10.7763/IJCEE.2009.V1.48

[19] JAIKLA, W., SILAPAN, P., CHANAPROMMA, C., SIRIPRUCHYANUN, M. Practical implementation of CCTA based on commercial CCII and OTA. In International Symposium on Intelligent Signal Processing and Communication Systems. Thailand, 2008. p. 1-4. ISBN: 978-1-4244-2564-8. DOI: 10.1109/ISPACS.2009.4806670

[20] PROKOP, R., MUSIL, V. CCTA: a new modern circuit block and its internal realization. In Electronic Devices and Systems IMAPS CZ International Conference. Brno (Czech Republic), 2005, p. 89 to 93. ISBN: $80-214-2990-9$

[21] SUMMART, S., SAETIAW, C., THONGSOPA, C., JAIKLA. W. CCTA based current mode first order filter and its application in quadrature oscillator. Przeglad Elektrotechniczny, 2013, vol. 89, no. 6, p. 104-108. ISSN: 0033-2097

[22] BUMRONGHOKE, T., JAIKLA, W., SIRIPRUCHYANUN, M. An electronic controllable, simple current-mode oscillator using single MO-CCCCTA and grounded capacitors. In Proceedings of the 1st International Conference on Technical Education (ICTE2009). Thailand, 2010. p. 217-220. Available at: http://www.te.kmutnb.ac.th/ msn/49_P009_217.pdf

[23] SIRIPRUCHYANUN, M., JAIKLA, W. Current controlled current conveyor transconductance amplifier (CCCCTA): a building block for analog signal processing. Electrical Engineering, 2008, vol. 90, no. 6, p. 443-453. ISSN: 0948-7921. DOI: $10.1007 / \mathrm{s} 00202-007-$ 0095-X

[24] SA-NGIAMVIBOOL, W., JANTAKUN, A. Quadrature oscillator using CCCCTAs and grounded capacitors with amplitude controllability. International Journal of Electronics, 2014, vol. 101, no. 12 , p. 1737-1758. ISSN: 0020-7217. DOI: $10.1080 / 00207217.2014 .896038$

[25] LINARES-BARRANCO, B., RODRIGUEZ-VAZQUEZ, SANCHEZ-SINENCIO, E., HUERTAS, J. L. 10MHz CMOS OTA-C voltage-controlled quadrature oscillator. Electronics Letters, 1989 , vol. 25 , no. 12 , p. 765-767. ISSN: 0013-5194. DOI: 10.1049/el:19890517

[26] LAHIRI, A. New current-mode quadrature oscillators using CDTA. IEICE Electronics Express, 2009, vol. 6, no. 3, p. 135-140. ISSN: 1349-2543. Available at: http://doi.org/10.1587/elex.6.135

[27] LI, Y. A. Electronically tunable current-mode quadrature oscillator using single MCDTA. Radioengineeing, 2010, vol. 19, no. 4, p. 667-671. ISSN: $1210-2512$

[28] DUANGMALAI, D, MANGKALAKEEREE, S., SIRIPRUCHYANUN, M. High output-impedance current-mode quadrature oscillator using single MO-CCCDTA. In The 7th PSU Engineering Conference. Songkla (Thailand), 2009, p. 287-290. Available at: http://www.te.kmutnb.ac.th/ msn/ cdtaoscpec 7.pdf

[29] JAIKLA, W., LAHIRI, A. Resistor-less current-mode four-phase 
quadrature oscillator using CCCDTAs and grounded capacitors. $A E \ddot{U}$-International Journal of Electronics and Communications, 2012, vol. 66, no. 3, p. 214-218. ISSN: 1434-8411. DOI: 10.1016/j.aeue.2011.07.001

[30] UTTAPHUT, P. Realization of electronically tunable current-mode multiphase sinusoidal oscillators using-CFTAs. World Academy of Science, Engineering and Technology, 2012, vol. 6, no. 9, p. 643 to 646. Available at: http://waste.org/publications/6037/

[31] TANGSRIRAT, W., MONGKOLWAI, P., PUKKALANUN, T. Current-mode high-Q filter and mixed-mode quadrature oscillator using ZC-CFTAs and grounded capacitors. Indian Journal of Pure \& Physics, 2012, vol. 50, no. 8, p. 600-607. ISSN: 0019-5596

[32] SOTNER, R., JERABEK, J., HERENCSAR, N., PETRZELA, J., VRBA, K., KINCL, Z. Linearly tunable quadrature oscillator derived from LC Colpitts structure using voltage differencing transconductance amplifier and adjustable current amplifier. Analog Integrated Circuits and Signal Processing, 2014, vol. 81, no. 1, p. 121-136. ISSN: 0925-1030. DOI: 10.1007/s10470-0140353-6
[33] SOTNER, R., HRUBOS, Z., HERENCSAR, N., JERABEK, J., DOSTAL, T., VRBA, K. Precise electronically adjustable oscillator suitable for quadrature signal generation employing active elements with current and voltage gain control. Circuits Systems and Signal Processing, 2014, vol. 33, no. 1, p. 1-35. ISSN: 0278-081X. DOI: 10.1007/s00034-013-9623-2

\begin{abstract}
About the Author ...
YongAn LI was born in 1961, received BS from Northwestern University (in China) in 1983. He is currently a professor at School of Physics and Electronic Engineering, Xianyang Normal University, China, and is studying on analog signal processing circuits and current-mode circuits. He has authored several international journal papers and has acted as a reviewer for several international journals.
\end{abstract}

